\title{
VALIDATED THIN-LAYER CHROMATOGRAPHY/DENSITOMETRY METHOD FOR THE ANALYSIS OF ANTI- ALZHEIMER DRUG IN BULK AND IN CAPSULE FORMULATION
}

\author{
MOHAMMAD MOJEEB GULZAR KHAN* AND ATUL ARUN SHIRKHEDKAR
}

Department of Pharmaceutical Chemistry, R. C. Patel Institute of Pharmaceutical Education and Research, Shirpur, Dist: Dhule (MS) 425405 India

\begin{abstract}
A simple, sensitive and precise Thin-Layer Chromatography (TLC)/ Densitometry method has been developed for estimation of Rivastigmine hydrogen tartrate [RVT] in bulk and in capsule formulation. The chromatographic separation was accomplished on aluminium backed precoated silica gel $60 \mathrm{~F}_{254}$ as the stationary phase using $n$ - Hexane: Ethyl acetate: triethylamine $(1.5: 8.5: 0.3 \mathrm{v} / \mathrm{v})$ as mobile phase. The $R_{\mathrm{F}}$ value was observed to be $0.46 \pm 0.02$ for RVT when the sports were analyzed densitometrically at $213 \mathrm{~nm}$. The method was linear in the range of $1000-6000 \mathrm{ng}^{\mathrm{F}}$ band $^{-1}$ with coefficient correlation value 0.9990 . RVT was subjected to acid, alkali hydrolysis, oxidation, dry heat degradation and photo degradation. The degraded product peaks were well resolved from the pure drug peak with significant difference in their $R_{\mathrm{F}}$ values. Analysis of drug was performed in the presence of degraded samples. The proposed method validated for linearity, accuracy, precision and robustness. The developed TLC-densitometric method can be used as an alternative method for the precise assay of rivastigmine hydrogen tartrate in capsules form because it fulfils the validation criteria of an analytical method designated for quantity control of pharmaceutical preparations.
\end{abstract}

Keywords: Rivastigmine hydrogen tartrate, RVT, HPTLC, Stability-indicating, Validation

\section{INTRODUCTION}

Rivastigmine hydrogen tartrate (RVT) (S)-N-Ethyl-N-methyl-3[1(dimethylamino) ethyl]-phenyl carbamate hydrogen-(2R, 3R)-tartrate (Figure 1) is a cholinesterase inhibitor and used to treat mild to moderate Alzheimer disease ${ }^{1-3}$. A literature survey revealed Liquid chromatographic- Tandem Mass spectrometry method for estimation of Rivatigmine and its major metabolite in human plasma and rat brain has been established ${ }^{4,5}$. Enantiomeric separation RVT has been studied ${ }^{6}$. Stability- indicating liquid- chromatographic method have been developed ${ }^{7}$, and identification and characterization of new impurities in RVT has been discussed ${ }^{8}$. A spectrophotometric method using complex mobile phase has been studied for estimation of RVT in bulk and pharmaceutical formulations 9 .

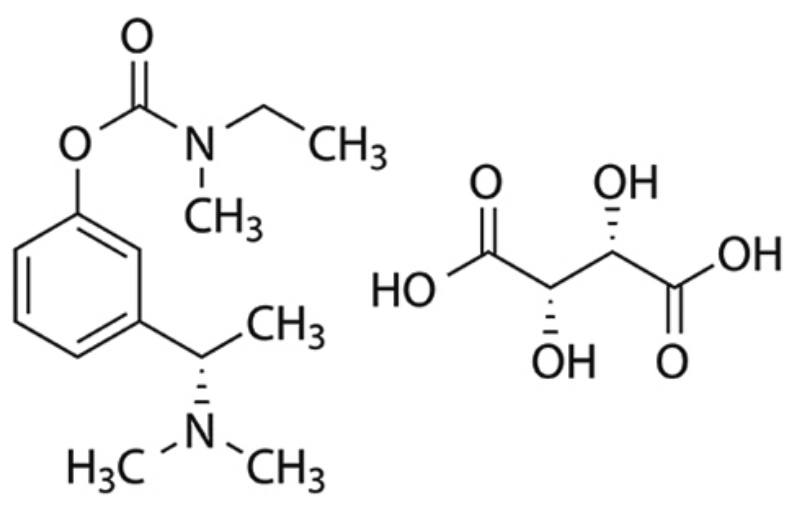

Fig .1: Chemical structure of Rivastigmine hydrogen tartrate

High- Performance Thin- Layer Chromatography (HPTLC) is one of the routinely used analytical techniques due to its low operational cost; high sample through put and required minimum sample clean up. The major advantage of HPTLC is that several samples can be run simultaneously using a small quantity of mobile phase unlike HPLC; thus lowering analysis time and cost per analysis ${ }^{10}$.

The objective of the present work is to establish a simple, precise and accurate TLC/Densitometry method for analysis of RVT in the bulk material and in capsule formulation. Further, the develop analytical method has to be validated for accuracy, precision, ruggedness and robustness, sensitivity, specificity and stability study is carried out as per ICH guidelines ${ }^{11,12}$.

\section{EXPERIMENTAL}

\subsection{Instrument and Chromatographic Condition}

A Camag TLC system (Muttens, Switzerland) comprising of Camag Linomat 5 automatic sample applicator, Hamilton syringe $(100 \mu 1)$, Camag TLC scanner 3, with winCATS software (1.3.0), Camag twin trough chamber $(20 \times 10 \mathrm{~cm})$ and ultra sonicator was used during the study. TLC plates used were aluminium backed precoated silica gel $60 \mathrm{~F}_{254},[(20 \times 10 \mathrm{~cm})$ with $250 \mu \mathrm{m}$ thickness; E. Merck, Darmstadt, Germany, supplied by Anchrom Technologists, Mumbai]. The plates were pre-washed with methanol and activated at $110^{\circ} \mathrm{C}$ for $5 \mathrm{~min}$, prior to chromatography. A constant application rate of $150 \mathrm{~nL} \mathrm{~s}^{-1}$ was employed and space between two bands was $15.4 \mathrm{~mm}$. The slit dimension was kept at $6 \mathrm{~mm} \times 0.45 \mathrm{~mm}$. The mobile phase consisted of $n$ - Hexane: Ethyl acetate: triethylamine (1.5: 8.5:0.3 v/v). Linear ascending development was carried out in $20 \mathrm{~cm} \times 10 \mathrm{~cm}$ twin trough glass chamber (Camag, Muttenz, Switzerland). The optimised chamber saturation time for mobile phase was $20 \mathrm{~min}$, at temperature $\left(25^{\circ} \mathrm{C}\right)$ the relative humidity $(60 \% \pm$ $5 \%$ ) the length of chromatogram run was $8 \mathrm{~cm}$ and TLC plates were air dried. Densitometric scanning was performed at $213 \mathrm{~nm}$. The source of radiation utilised was deuterium lamp. Evaluation was performed using peak area with linear regression.

\subsection{Materials and Reagents}

Rivastigmine hydrogen tartrate (99.5\%) was obtained as gift samples from Cipla Pharmaceutical Ltd Mumbai. Ethyl acetate, $n$-Hexane and triethylamine were used of HPLC grade.

2.3 Preparation of Stock Standard and sample solution

Stock standard solution was prepared by dissolving $10 \mathrm{mg}$ of RVT in 10 $\mathrm{mL}$ methanol that gives concentration of $1000 \mu \mathrm{g} \cdot \mathrm{mL}^{-1}$

To determine the content of RVT in capsules, the content of the twenty capsules were weighed the average weight determined. A quantity of powder equivalent to $10 \mathrm{mg}$ of RVT was transferred in to $50 \mathrm{~mL}$ volumetric flask containing $20 \mathrm{~mL}$ methanol, shaken manually for $30 \mathrm{~min}$ and diluted to mark with same solvent. The resulting solution was filtered using $0.45 \mu \mathrm{m}$ filter (Millifilter, Milford, MA, USA) and $20 \mu \mathrm{L}$ equivalent to 4000 ng RVT was applied to a plate for assay of the drug.

\subsection{Study of Linearity Curve}

The linearity study verifies and approves that the sample solutions are in a concentration range where analyte response is linearly proportional to the concentration. From the stock standard solutions, an appropriate volumes in the range of $1-6 \mu \mathrm{L}$ were applied on to the TLC plates to obtain concentration $1000,2000,3000,4000,5000$ and $6000 \mathrm{ng}$ per band of RVT, respectively. Each concentration was applied six times on TLC plates and developed as described in section 2.1. Peak area plotted against corresponding amount to obtain the calibration plot.

\subsection{Method Validation}

2.5.1. Precision 
Precision of the method was studied as intra-day and inter-day variations and as repeatability. Intra - day precision was determined by analyzing, the three different concentrations (3000, 4000 and $5000 \mathrm{ng}$ per band) for three times in the same day. Day - to Day variability was assessed using abovementioned three concentrations analyzed on three different days, over a period of one week. This result shows reproducibility of the assay. To determine system precision, repeatability of sample application and measurement of RVT peak area was measured by performing six replicate analysis of same concentration (4000 ng per band).

\subsubsection{Robustness and Ruggedness}

The robustness of an analytical procedure is a measure of its capacity to stay unchanged by small, but intentional changes in the method parameters and provides an indication of its reliability during normal day-to-day usage. The robustness of method was demonstrated by performing test method by studying different parameters like mobile phase volume, mobile phase composition, development distance, duration of saturation, time from spotting to chromatography and chromatography to spotting were studied and the effects on the results were examined. The ruggedness of the proposed method was evaluated by two different analysts using same environmental and experimental condition. The robustness and ruggedness of the method was assessed at concentration (3000 ng per band).

2.5.3 Limit of Detection (LOD) and limit of Quantification (LOQ)

In order to determine detection and quantification limit, concentration in the lower part of the linear range of the calibration curve used. The amount of RVT by spot versus peak area was graphed and the equation for this was obtained, The average of standard deviation calculated. Detection limit was calculated by $(3.3 \times$ A.S.D $) / b$ and Quantification limit was calculated by $(10 \mathrm{x}$ A.S.D) $/ b$ where, $b$, correspond to slope obtained in graph.

\subsubsection{Specificity}

Specificity of an analytical method is its ability to measure accurately and specifically the concentration of analyte(s) of interest without interference from other API, diluents, mobile phase. The specificity of the method was established by analysis of drug standards and samples and comparing the $R_{\mathrm{F}}$ value and spectrum of RVT band from samples with those of the band from standard. The peak purity of RVT was assessed by comparing spectra at three different positions on the band, i.e. peak-start (S), peak-apex (M), and peakend $(\mathrm{E})$

\subsubsection{Accuracy}

Accuracy of a method is defined as the closeness of measured value to the true value for the samples. To study the recovery of the drug at different levels in formulations, pre-analysed samples were spiked with $80 \%, 100 \%$, and 120 $\%$ extra RVT standard and re-analysed by use of the method.

2.6. Forced Degradation Study

Acid and base-induced degradation was attempted by separately adding $10 \mathrm{mg}$ of RVT in $10 \mathrm{~mL}$ each of $0.1 \mathrm{~N} \mathrm{HCl}$ and $0.1 \mathrm{~N} \mathrm{NaOH}$ solutions. These solutions were kept for $8 \mathrm{~h}$ at $60^{\circ} \mathrm{C}$ in the dark in order to exclude the possible degradative effect of light. The solutions $(1 \mathrm{~mL})$ were neutralized and diluted to $10 \mathrm{~mL}$ with methanol. A constant volume $60 \mu \mathrm{L}$ of the resulting solutions (6000 ng per band) were applied to a TLC plate and chromatograms were obtained as described in section 2.1. For oxidative degradation, 10 $\mathrm{mg}$ of RVT added in $10 \mathrm{~mL}$ of $3 \%(v / v)$ hydrogen peroxide solution. These mixtures were kept for $8 \mathrm{~h}$. The solution $(1 \mathrm{~mL})$ were diluted to $10 \mathrm{ml}$ with methanol and treated as described for acid and base-induced degradation. To assess the neutral degradation, a $10 \mathrm{mg}$ of RVT added in $10 \mathrm{~mL}$ methanol and photochemical degradation was studied by exposing to sun light for $72 \mathrm{~h}$. The resulting solution was applied on plate $(6 \mu \mathrm{L}$ each, i.e $6000 \mathrm{ng}$ per band $)$ and chromatogram was obtained as described in section 2.1. for dry heat study Riva $10 \mathrm{mg}$ was stored at $60^{\circ} \mathrm{C}$ for $3 \mathrm{~h}$ in oven separately, then transferred to $10 \mathrm{ml}$ volumetric flask containing methanol and volume was made up to the mark. $0.6 \mu 1(6000 \mathrm{ng} / \mathrm{spot})$ was applied on TLC plate in triplicate and chromatogram were run as described above.

\section{RESULTS AND DISCUSSION}

\subsection{Optimisation of TLC/ Densitometry method}

To develop the TLC/Densitometry method for the estimation of RVT, selection of the mobile phase was carried out on the basis of polarity. Initially, combination of various proportions of solvents n- hexane and ethyl acetate were tried as mobile phase but diffusion of the spots and tailing was observed. To avoid the problem, $0.3 \mathrm{ml}$ of triethylamine was added as modifier. Finally, mobile phase composed of n- Hexane: Ethyl acetate: $(1.5: 8.5: 0.3 \mathrm{v} / \mathrm{v})$ was established as observed to well resolved and spot with $R_{\mathrm{F}}$ value $0.46 \pm 0.02$ when plate was developed and scanned at $213 \mathrm{~nm}$; (Figure 2). The chamber was saturated with the mobile phase for $20 \mathrm{~min}$ at room temperature and plates were activated at $110^{\circ} \mathrm{C}$ for 5 min to obtain well defined spots.

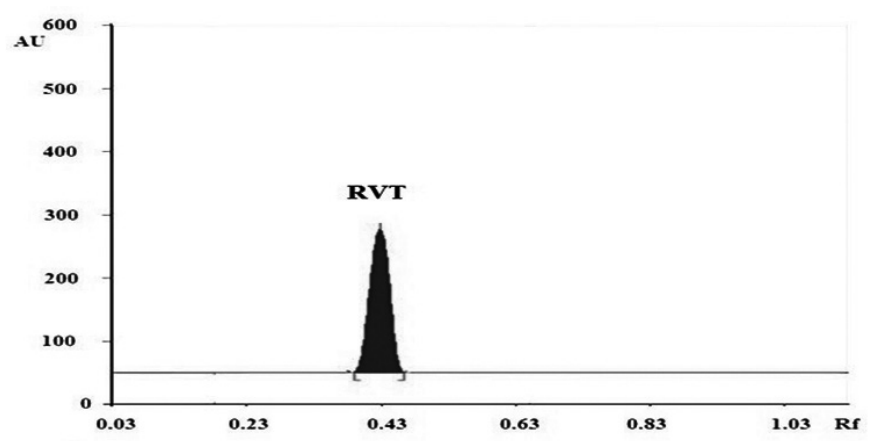

Fig.2: Densitogram of RVT showing $R_{\mathrm{F}}$ value 0.46 at $213 \mathrm{~nm}$

\subsection{Study of calibration curve}

Linearity responses for RVT assessed in the concentration range 1000$6000 \mathrm{ng} / \mathrm{band}$. The linear equation for the calibration plot was $\mathrm{y}=1.1285 \mathrm{x}+$ 602.5733 with correlation coefficient ( $r$ ) found to be 0.9990 (Figure 3 ). Linearity range was established with five replicate readings of each concentration.
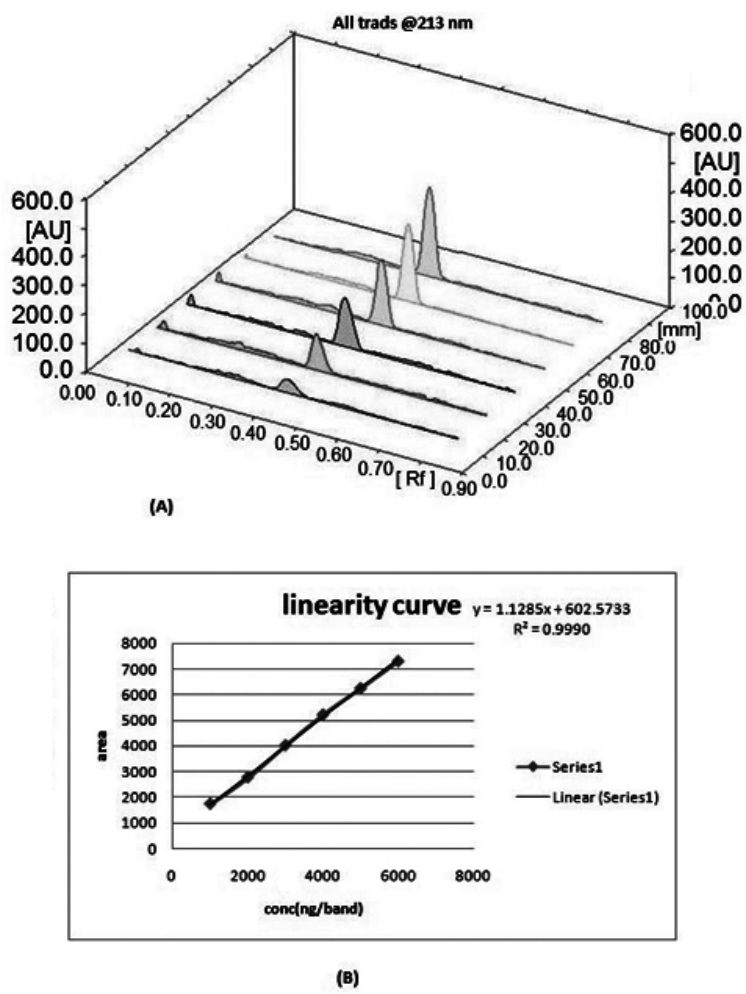

Fig.3: (A) Linearity of RVT (3D) (B) calibration curve Of RVT

\subsection{Validation of Method}

\subsubsection{Precision}

The precision of the method were expressed as a percentage relative standard deviation (RSD [\%]).The \% RSD measured in the study of intra-day and inter-day precision was found to be 0.10 and $0.23 \%$, respectively. $\%$ RSD in the repeatability study was found to be $0.15 \%$. (\% RSD). Since the $\%$ RSD is $<2 \%$ indicates method is precise.

3.3.2. Robustness and Ruggedness

As shown in Table 1, $\% \mathrm{RSD}<2 \%$ indicates robustness of the method. 
Table 1: Results from assessments of the robustness of the method ${ }^{a}$

\begin{tabular}{|c|c|c|}
\hline Robustness parameter & $R_{\mathrm{F}}$ & $\%$ RSD \\
\hline \multicolumn{3}{|c|}{$\begin{array}{c}\text { Change in Mobile Phase Composition ( } n \text { - Hexane: Ethyl acetate: } \\
\text { triethylamine) }\end{array}$} \\
\hline $1.5: 8.5: 0.3 v / v$ & 0.46 & 0.89 \\
\hline $2: 8: 0.3 \mathrm{v} / \mathrm{v}$ & 0.45 & 0.82 \\
\hline $1.8: 8.2: 0.2 v / v$ & 0.47 & 0.71 \\
\hline Mean & 0.46 & 0.80 \\
\hline \multicolumn{3}{|c|}{ Mobile Phase Volume } \\
\hline $08 \mathrm{~mL}$ & 0.45 & 0.69 \\
\hline $10 \mathrm{~mL}$ & 0.46 & 0.61 \\
\hline $12 \mathrm{~mL}$ & 0.45 & 0.55 \\
\hline Mean & 0.45 & 0.61 \\
\hline \multicolumn{3}{|c|}{ Duration of saturation } \\
\hline $15 \mathrm{~min}$ & 0.46 & 1.50 \\
\hline $18 \mathrm{~min}$ & 0.44 & 1.26 \\
\hline $12 \mathrm{~min}$ & 0.46 & 1.28 \\
\hline Mean & 0.45 & 1.34 \\
\hline \multicolumn{3}{|c|}{ Development distance } \\
\hline $7 \mathrm{~cm}$ & 0.43 & 1.20 \\
\hline $7.5 \mathrm{~cm}$ & 0.45 & 0.80 \\
\hline $8 \mathrm{~cm}$ & 0.46 & 0.75 \\
\hline Mean & 0.44 & 0.91 \\
\hline \multicolumn{3}{|c|}{ Chromatographic Changes (Time from application to development) } \\
\hline $0 \mathrm{~min}$ & 0.45 & 1.49 \\
\hline $10 \mathrm{~min}$ & 0.46 & 0.90 \\
\hline $15 \mathrm{~min}$ & 0.45 & 1.60 \\
\hline $20 \mathrm{~min}$ & 0.47 & 1.70 \\
\hline Mean & 0.45 & 1.42 \\
\hline \multicolumn{3}{|c|}{ Time from development to scanning } \\
\hline $0 \mathrm{~min}$ & 0.45 & 0.94 \\
\hline $20 \mathrm{~min}$ & 0.46 & 1.50 \\
\hline $1 \mathrm{hr}$ & 0.46 & 0.80 \\
\hline $1 \mathrm{hr} 30 \mathrm{~min}$ & 0.46 & 1.47 \\
\hline Mean & 0.46 & 1.18 \\
\hline
\end{tabular}

${ }^{a}$ Results are averages from six determinations

The $\%$ RSD of results of analysis by two analysts were calculated and found to be $0.73 \%$ and $0.83 \%$, respectively. Since, there was no statistically difference between the assay results obtain by each analyst the method proved to be rugged.

3.3.3. Limit of Detection (LOD) and Limit of Quantification (LOQ) Detection limit (LOD) of $97.01 \mathrm{ng}$ and (LOQ) of $293.94 \mathrm{ng}$ were achieved under the analytical conditions mentioned above (2.5.3).

3.3.4. Specificity

(Figure 4) showed the results obtained from assessment of the purity of the RVT peak by comparison of spectra acquired at the peak-start, peak- apex, and peak-end position of the band.

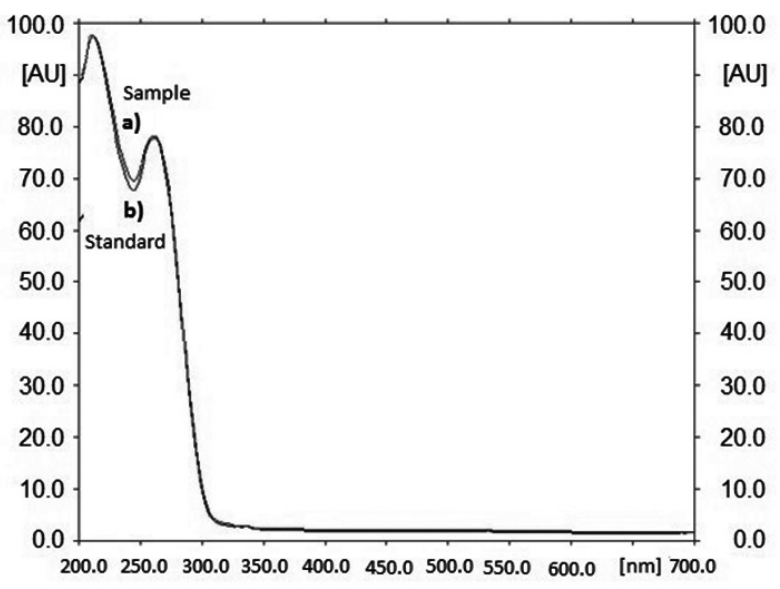

Fig.4: Overlain spectra of RVT sample [a] and RVT Standard[b] scanned at the peak start, peak apex, and peak end position of the band.

3.3.5. Recovery

The results obtained from determination of recovery are listed in Table 2; the low \% RSD values indicative of the accuracy of the method.

Table 2: Results of recovery studies ${ }^{\text {a }}$

\begin{tabular}{|c|c|c|c|c|}
\hline \multirow{2}{*}{ Component } & $\begin{array}{c}\text { Label } \\
\text { claim(mg/ } \\
\text { capsule) }\end{array}$ & $\begin{array}{c}\text { \% amount } \\
\text { of standard } \\
\text { drug added }\end{array}$ & $\begin{array}{c}\text { \%drug } \\
\text { recovered }\end{array}$ & \%RSD \\
\hline \multirow{2}{*}{ RVT } & \multirow{2}{*}{4.5} & 80 & 99.28 & 0.27 \\
\cline { 3 - 5 } & & 100 & 98.92 & 0.33 \\
\cline { 3 - 5 } & & 120 & 100.08 & 0.11 \\
\hline
\end{tabular}

a Results are averages from three determination at each level

3.4 Assay of Marketed Formulation

A band at $R_{\mathrm{F}} 0.46$ for RVT was observed in the densitogram. The drug content was found to be $99.98 \%$, with $\%$ RSD 0.23 . The low value is indicative of the suitability of method for routine analysis of RVT in pharmaceutical dosage forms.

\subsection{Force Degradation of RVT}

Forced Degradation study of RVT carried by action of acid, alkali, hydrogen peroxide, sunlight and dry heat showed that RVT was degraded in all stressed conditions and showed well resolved bands of RVT and additional peaks at different $R_{\mathrm{F}}$ values i.e. all the degradation product were resolved from RVT (Figure 5).

The percentage amount of RVT remaining and amount of RVT recovered [\%] were calculated $(\mathrm{n}=3)$; these values, and number of degradation products and their $R_{\mathrm{F}}$ values are given in Table 3 .

Table 3: Forced degradation of RVT.

\begin{tabular}{|c|c|c|}
\hline $\begin{array}{c}\text { Sample exposure } \\
\text { condition }\end{array}$ & $\begin{array}{c}\text { Number of degradation } \\
\text { products }\left(R_{\mathrm{F}} \text { value }\right)\end{array}$ & Recovery (\%) \\
\hline $\mathrm{HCl} 3 \mathrm{hr}$ & $3(0.07,0.38,0.64)$ & 89.15 \\
$\mathrm{NaOH} 9 \mathrm{hr}$ & $2(0.08,0.60)$ & 72.13 \\
$\mathrm{H}_{2} \mathrm{O}_{2} 3 \% 6 \mathrm{hr}$ & $2(0.09,0.65)$ & 88.85 \\
Photo $8 \mathrm{hr}$ & $3(0.27,0.32,0.50)$ & 70.33 \\
Heat $3 \mathrm{hr} 60^{\circ} \mathrm{C}$ & $4(0.12,0.19,0.27,0.31)$ & 76.60 \\
\hline
\end{tabular}


$\mathbf{A}$

B
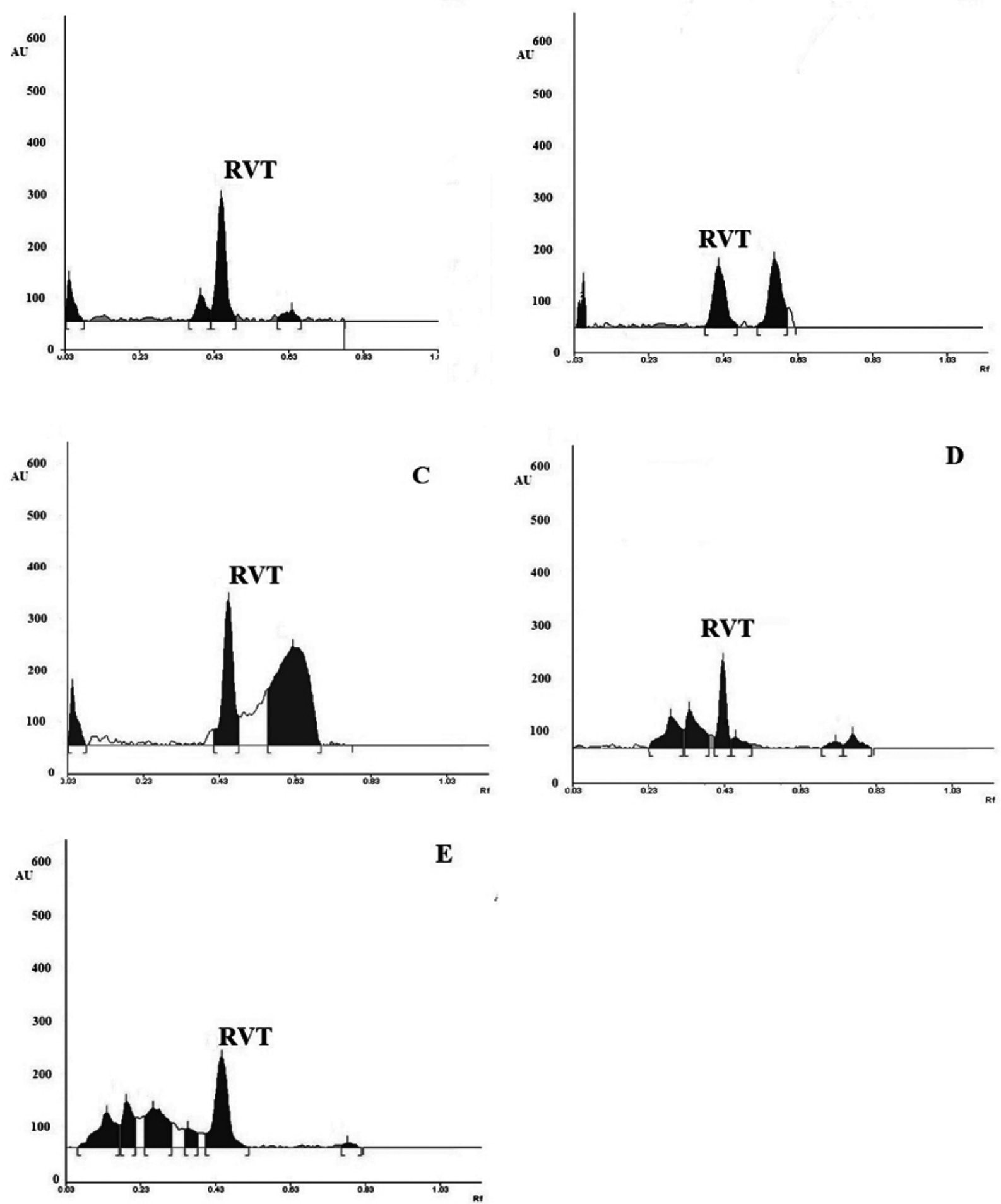

Fig.5: Forced Degradation study on RVT- (A): Acid degradation, (B): Alkali degradation, (C): Oxidative degradation, (D): Sunlight degradation, (E): Dry heat degradation 


\section{CONCLUSION}

The proposed TLC/ Densitometry method provides simple, accurate and reproducible quantitative analysis for estimation of Rivastigmine in capsule formulation. The method was validated as per ICH guidelines. The method is specific and there is no interference from any of the sample components. It can be concluded that the developed method offers several advantages such as rapid, cost effective, simple mobile phase and simple preparation steps, improved sensitivity and comparative short run time. Because method effectively separated the drug from the degradation products, it can be used as a stability-indicating method.

\section{CONFLICT OF INTEREST}

Authors have no conflict of interest

\section{ACKNOWLEDGEMENT}

The authors are thankful to Dr.S.J.Surana, Principal of R.C. Patel Institute of Pharmaceutical Education and Research, Shirpur (M.S.), India for providing the necessary facilities to carry out this research work

\section{REFERENCES}

1. M.J. O'Neill, P.E. Heckelman, C.B. Koch, K.J. Roman The Merck Index - An Encyclopedia of Chemicals, Drugs and Biologicals, Merck Research Laboratories, Whitehouse Station, New Jersey, USA, 2006
2. S.C. Sweetman Martindale: The Complete Drug Reference, The Pharmaceutical Press, London, 2002

3. R.A. Helms, D.J. Quan, E.T. Herfindal, D.R. Gourley Textbook of Therapeutics Drug and Disease Management, Lippincott Williams and Wilkin's, USA, 2006

4. F. Pommier, R. Frigola, J. Chromatogr. B. 784, 301, (2003)

5. A. Enz, A. Chappuis, A. Dattler, Biomed. Chromatogr. 18, 160, (2004)

6. M.K. Srinivasu, B.M. Rao, B.S.S. Reddy, P.R. Kumar, K.B. Chandrasekhar, P.K. Mohakhud, J. Pharm. Biomed. Anal. 38, 320, (2005)

7. B.M. Rao, M.K. Srinivasu, K.P.Kumar, N. Bhradwaj, R. Ravi, P.K. Mohakhud, G. Om Reddy, P.R. Kumar, J. Pharm. Biomed. Anal. 37, 57, (2005)

8. M. SrinivasaRao, S.V. Rao, D.V.N. SrinivasaRao, C. Bharathi, P. Rajput, H.K. Sharma, Die. Pharmazie. 65, 336, (2010)

9. M.Y. Salem, A.M. El-Kosasy, M.G. El-Bardicy, M.K. AbdEl-Rahman, Drug. Test. Anal. 2, 225, (2010)

10. P.D. Shethi HPTLC Quantitative Analysis of Pharmaceutical Formulation, CBS Publisher and Distributors, Delhi, 1996

11. Guideline, ICH Harmonized Tripartite, Validation of Analytical Procedures: Text and Methodology, Q2 (R1), 1, 2005

12. Guideline, ICH Harmonised Tripartite, Stability testing of new drug substances and products, Q1A (R2), 2003 